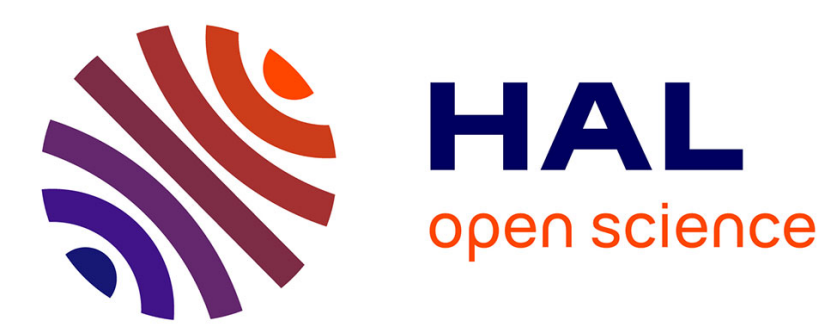

\title{
A Threshold Vector Autoregression Model of Exchange Rate Pass-Through in Mexico
}

\author{
Abdul Aleem, Amine Lahiani
}

\section{To cite this version:}

Abdul Aleem, Amine Lahiani. A Threshold Vector Autoregression Model of Exchange Rate Pass-Through in Mexico. Research in International Business and Finance, 2014, 30, pp.24-33. 10.1016/j.ribaf.2013.05.001 . halshs-01022416

\section{HAL Id: halshs-01022416 https://shs.hal.science/halshs-01022416}

Submitted on 7 Aug 2014

HAL is a multi-disciplinary open access archive for the deposit and dissemination of scientific research documents, whether they are published or not. The documents may come from teaching and research institutions in France or abroad, or from public or private research centers.
L'archive ouverte pluridisciplinaire HAL, est destinée au dépôt et à la diffusion de documents scientifiques de niveau recherche, publiés ou non, émanant des établissements d'enseignement et de recherche français ou étrangers, des laboratoires publics ou privés. 


\title{
A Threshold Vector Autoregression Model of Exchange Rate Pass-through in
}

\author{
Mexico \\ Abdul Aleem \\ Dalhousie University, Canada \\ aaleem@dal.ca \\ Amine Lahiani \\ LEO-University of Orléans, France \\ Amine.lahiani@univ-orléans.fr
}

\begin{abstract}
Considering nonlinearities in the exchange rate pass-through to domestic prices, this paper estimates exchange rate pass-through in Mexico. We examine responses of domestic prices to a positive one unit exchange rate shock by estimating a Threshold Vector Autoregression (TVAR) model. A monthly rate of inflation of $0.79 \%$ acts as a threshold. The exchange rate pass-through to domestic prices is statistically significant above the threshold level of the inflation rate and statistically insignificant below it.
\end{abstract}

Key words: Exchange rate pass-through, prices, threshold vector autoregression. JEL classification: E31, F31, F47 


\section{Introduction}

The credibility of monetary policy to stabilize inflation in the economy determines the degree of exchange rate pass-through. A way to measure monetary policy's credibility is the rate of inflation. Economic agents change inflationary expectations if the rate of inflation is higher than a threshold level. Firms perceive any increase in the cost of production beyond a certain threshold to be more persistent in the presence of high inflation rates. Therefore, in a high inflationary environment, they choose a higher frequency of price adjustment for a given menu cost. Firms transfer the effects coming from shocks on costs in order to maintain their mark up. Other things held constant, the exchange rate pass-through to domestic prices is higher during high inflationary episodes than low inflationary episodes. Using micro data for Argentina, Alvarez et al. (2011) found that the frequency of price adjustment is uncorrelated with current inflation for inflation rates below $10 \%$ and that this frequency has an elasticity close to $2 / 3$ for higher inflation rates.

It is worth noting that the exchange rate pass-through literature has seen the use of three econometric techniques i.e., the single equation regression, stationary Vector Autoregression (VAR) and cointegration. In the univariate process, the domestic prices are assumed to be exogenously determined by the exchange rate shocks. The VAR methodology has the advantage of measuring simultaneous relationships between exchange rate and other variables. This methodology has been widely used to examine the exchange rate pass-through. ${ }^{1}$ Given the presence of nonlinearities in the exchange rate pass-through, linear modelling techniques may

\footnotetext{
${ }^{1}$ McCarthy (1999), Choudhri et al. (2005), Takatoshi and Kiyotaka (2007), Zorzi et al. (2007). Bhundia (2002), Leigh and Rossi (2002), Billmeier and Bonato (2004), Korhonen and Wachtel (2006), and Sek and Kapsalyamova
} (2008). 
give imprecise exchange rate pass-through coefficients. A more realistic approach would be to recognize that the inflationary environment also affects the responses of economic agents to an exchange rate shock. It follows that domestic prices may not respond to an exchange rate shock due to the low and stable inflation. But they respond to the same shocks if the inflation is above its threshold level. Therefore, in this paper we use a multivariate process, the Threshold Vector Autoregression (TVAR) model, to study the exchange rate pass-through. The TVAR model is in line with the fact that movements in the exchange rate could alter the responses of economic agents to those changes and consequently these responses may correspond to different regimes depending on the rate of inflation.

During 1990s, a series of monetary policy reforms and subsequent transition to new policy regimes in post-crisis Latin American emerging economies increased the importance of nonlinear models. We estimate a TVAR model consisting of a set of variables that determine the exchange rate pass-through to domestic prices in Mexico. In December 1994, Mexico suffered from a currency crisis and it adopted a floating exchange rate regime. In 1996, the Central Bank of Mexico started a gradual transition towards an inflation targeting policy to control inflationary expectations, and it switched completely to inflation targeting policy in January $1999 .^{2}$

\footnotetext{
${ }^{2}$ Schemidt-Hebbel and Werner (2002), Levin et al. (2004)
} 
Figure 1. Annual rate of inflation and inflation targets in Mexico

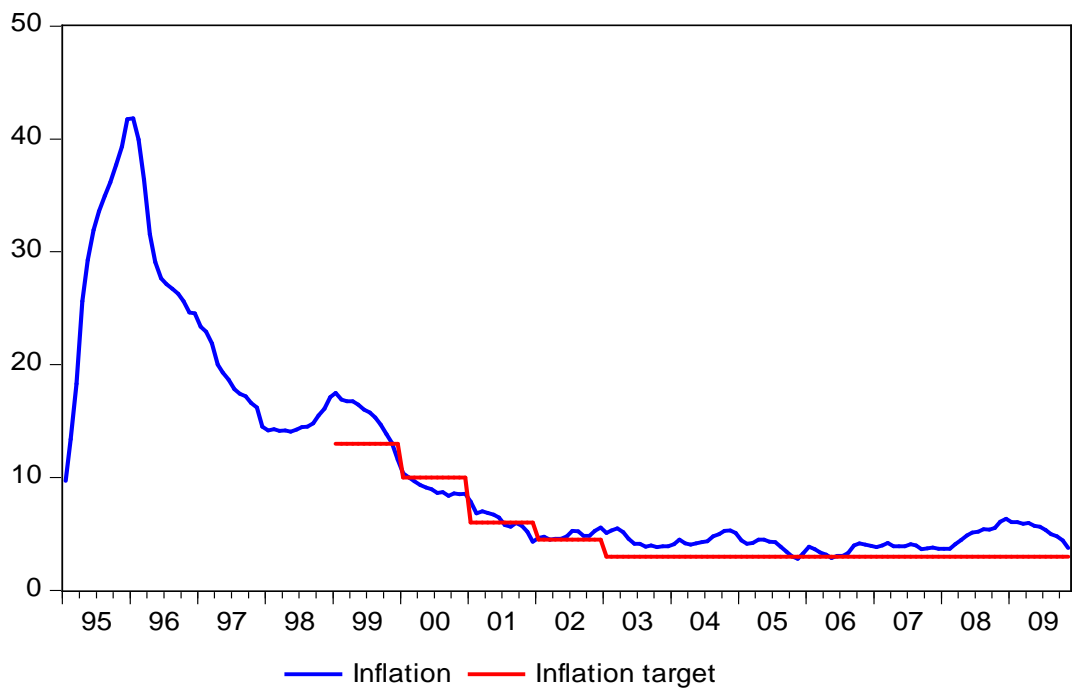

Source: International Financial Statistics, International Monetary Fund; Various inflation reports, The Bank of Mexico; and Authors' calculations

Figure 1 shows the rate of inflation in Mexico from 1994 to 2009. The figure also shows the inflation targets set by the Bank of Mexico. The Bank of Mexico set the first inflation target at $13 \%$ in January 1999 . Since 2003 , the Bank targets a rate of inflation at $3 \%$ with a variability interval of $+/-1 \%$. During this time period, significant changes in the rate of inflation in terms of its volatility and its mean level make Mexico particularly suitable to examine the exchange rate pass-through using a TVAR model.

We estimate the nonlinear responses of domestic prices to an exchange rate shock by taking into account the threshold levels of the rate of inflation. The contributions of this paper are threefold. First we estimate a nonlinear multivariate model by using the threshold level of inflation. The threshold level of inflation is determined endogenously. To our knowledge there is no work done in the context of exchange rate pass-through using endogenously determined threshold level of inflation. Second, we allow for a simultaneous regime switching in our TVAR 
model. Third, we allow for the presence of more than two regimes and test for the presence of three regimes.

We review the previous literature to find possible causes of nonlinear exchange rate passthrough in the next section. In section 3, we present the TVAR model to estimate the nonlinear exchange rate pass-through to domestic prices. In section 4, we present the estimation methodology. In section 5, we present the empirical findings. Finally, we set out our conclusions in section 6. Data definitions and sources are summarized in the appendix.

\section{Nonlinearities in exchange rate pass-through}

Previous empirical studies show a positive relationship between the exchange rate passthrough and the inflationary environment. Taylor (2000) found that the responsiveness of prices to fluctuations in the exchange rate depends positively on the level of inflation. He argued that low exchange rate pass-through in low inflation countries is a result of the low inflation environment. Choudhri et al. (2005) found that countries having high rates of inflation are often characterised by high exchange rate pass-through coefficients. Baqueiro et al. (2003) examined the exchange rate pass-through in different countries by splitting the sample period of each country into high and low inflation regimes. They found that the exchange rate pass-through is higher in high inflationary episodes than in low inflationary episodes. These findings suggest that the relationship between the degree of exchange rate pass-through to domestic prices and inflationary environment is nonlinear. 
Figure 2. Exchange rate depreciation and inflation in Mexico

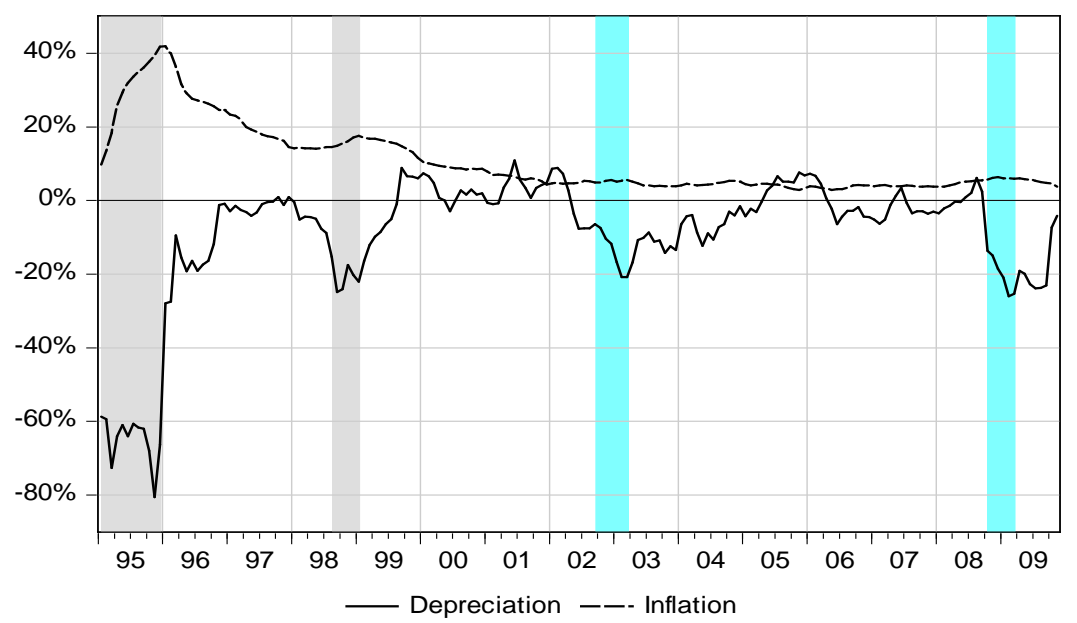

Source: International Financial Statistics, International Monetary Fund; Bank of International Settlements; and Authors' calculations

Note: The exchange rate depreciation is defined as the annualized changes in exchange rate indices. A negative index means a depreciation and vice versa.

Figure 2 shows the exchange rate devaluation and inflation in Mexico from 1994 to 2009. The exchange rate depreciation increased from $-15.3 \%$ in August 1998 to $-20.2 \%$ in December 1998 and the inflation increased from $14.5 \%$ to $17.1 \%$ during the same period. However, the inflation rose from 5.5\% in October 2008 to 5.9\% in March 2009 when the exchange rate depreciation increased from $-13.8 \%$ to $-25.3 \%$. The relationship between inflation and exchange rate depreciation is positive in two episodes, but the change in inflation is negligible in the latter episode of exchange rate depreciation. Previous empirical studies explain the nonlinear relationship between exchange rate and inflation in several ways. Al-Abri and Goodwin (2009) argued for a significant threshold cointegration relationship between the nominal effective exchange rate and import prices. They showed that the degree of exchange rate pass-through improves from the $50 \%$ average documented in the literature once a threshold is detected. 
Pollard and Coughlin (2004) found that most firms respond asymmetrically to large and small changes in the exchange rate with pass-through positively related to the size of the change. Josip and Petra (2009) employed the Threshold Autoregressive model to estimate the exchange rate pass-through in Croatia, and showed that a certain level of devaluation acts as a threshold between the two regimes. They found that below the threshold, there is no exchange rate passthrough to prices and above the threshold there is a complete pass-through to prices. But, the historical data on exchange rate depreciation and inflation in Mexico shows that the inflation responds significantly to exchange rate depreciation if the rate of inflation only if the rate of inflation is above certain level. As long as, the rate of inflation is below that level, the response of inflation to exchange rate depreciation remains insignificant. It necessitates the estimation of the threshold levels of inflation in the first step, and the analysis of the responses of domestic prices to exchange rate shocks in different inflationary regimes in the second step.

\section{The Threshold Vector Autoregression (TVAR) model}

We estimate the following three regime TVAR model:

$$
y_{t}= \begin{cases}\alpha_{1}+A_{1}(L) y_{t}+\varepsilon_{1 t} & \text { if } q_{t} \leq \gamma_{1} \\ \alpha_{2}+A_{2}(L) y_{t}+\varepsilon_{2 t} & \text { if } \gamma_{1}<q_{t} \leq \gamma_{2} \\ \alpha_{3}+A_{3}(L) y_{t}+\varepsilon_{3 t} & \text { if } q_{t}>\gamma_{2}\end{cases}
$$

where the vector of variables $\left(y_{t}\right)$ consists of the rate of inflation $(\pi)$, the output gap, the nominal effective exchange rate (NEER) and an indicator of the stance of monetary policy $(i)$. The output gap captures the effects of the real sector on exchange rate pass-through. We include an indicator of the stance of monetary policy in the vector of variables to take into account the effects of the monetary policy on exchange rate pass-through.

$$
y_{t}=\left[\begin{array}{llll}
\pi & \text { Outputgap } & \text { NEER } & i
\end{array}\right]
$$


$q_{t}$ is the threshold variable, and $\gamma_{1}$ and $\gamma_{2}$ are the threshold values. We treat the rate of inflation as the threshold variable in our model. $\alpha_{i}^{\prime}, \mathrm{i}=1, \ldots, 3$, is a $3 \times 1$ is vector of constants while the lagpolynomial $A_{i}(L)=A_{i 1} L+A_{i 2} L^{2}+\ldots+A_{i p} L^{p}$ with a $4 \times 4 p$ matrix $A_{i j}, j=1,2, \ldots, p ; L$ is the lag operator.

A more compact form of the three regime $\operatorname{TVAR}(p)$ model is as follows:

$$
\begin{aligned}
y_{t}= & \left(\alpha_{1}+A_{11}(L) y_{t-1}+\ldots+A_{1 p}(L) y_{t-p}+\varepsilon_{1 t}\right) I\left(q_{t} \leq \gamma_{1}\right)+\left(\alpha_{2}+A_{21}(L) y_{t-1}+\ldots+A_{2 p}(L) y_{t-p}+\varepsilon_{2 t}\right) I\left(\gamma_{1}<q_{t} \leq \gamma_{2}\right) \\
& +\left(\alpha_{3}+A_{31}(L) y_{t-1}+\ldots+A_{3 p}(L) y_{t-p}+\varepsilon_{3 t}\right) I\left(q_{t}>\gamma_{2}\right)
\end{aligned}
$$

where $I($.$) takes the value 1$ if its argument is satisfied and 0 otherwise.

It is worth noting that when $\gamma_{1}=\gamma_{2}$, the three regime TVAR model reduces to a two regime TVAR model.

Defining $\theta=\left(\alpha_{1}, \alpha_{2}, \alpha_{3}, A_{1}, A_{2}, A_{3}, \gamma_{1}, \gamma_{2}\right)$ as the vector of parameters of interest, we use the ordinary least square (OLS) method to minimise the following function:

$$
\hat{\theta}=\underset{\theta}{\arg \min }\left(\sum_{t=1}^{T}\left(\begin{array}{l}
y_{t}-\left(\alpha_{1}+A_{11}(L) y_{t-1}+\ldots+A_{1 p}(L) y_{t-p}+\varepsilon_{1 t}\right) I\left(q_{t} \leq \gamma_{1}\right) \\
-\left(\alpha_{2}+A_{21}(L) y_{t-1}+\ldots+A_{2 p}(L) y_{t-p}+\varepsilon_{2 t}\right) I\left(\gamma_{1}<q_{t} \leq \gamma_{2}\right) \\
-\left(\alpha_{3}+A_{31}(L) y_{t-1}+\ldots+A_{3 p}(L) y_{t-p}+\varepsilon_{3 t}\right) I\left(q_{t}>\gamma_{2}\right)
\end{array}\right)\right)
$$

\section{Estimation methodology}

\subsection{Data description}

We use monthly seasonally adjusted data from January 1994 to November 2009. The exchange rate is the nominal effective exchange rate computed by the Bank for International 
Settlements $(\mathrm{BIS})^{3}$. We define a shock to the exchange rate as a positive variation of the exchange rate. Thus, a positive variation of the exchange rate represents an appreciation of the domestic currency. The rate of inflation is measured by the Consumer Price Index (CPI). It is a widely used indicator by both financial analysts and policy makers to examine developing price trends and is generally considered as an indicator of the inflationary process in the economy. ${ }^{4}$ The exchange rate affects import prices which in turn affect production costs and consequently the CPI. The output gap is created by taking the deviations of the logarithm of real GDP from the trend estimates ${ }^{5}$. The overnight interbank rate has been shown to be a good indicator of the monetary policy stance. ${ }^{6}$ The Bank of Mexico has been using the target for overnight interbank rate as policy instrument since January 2008.

\footnotetext{
${ }^{3}$ We use the broad index of the nominal effective exchange rate. It is calculated as a geometric weighted average of bilateral exchange rates comprising of a basket of 42 countries. The weights are based on trade in 2005-07.

${ }^{4}$ Brière and Signori (2012); Granville and Mallick (2006).

${ }^{5}$ To calculate the trend estimates, we decompose the real GDP $\left(y_{t}\right)$ into two components; the trend component $\left(g_{t}\right)$ and the cyclical component $\left(c_{t}\right)$, i.e., $y_{t}=g_{t}+c_{t}$. We extract the trend component by minimizing $\operatorname{Min}_{t} \sum_{t=1}^{T}\left(y_{t}-g_{t}\right)_{t}^{2}+\lambda \sum_{t=1}^{T}\left[\left(g_{t}-g_{t-1}\right)-\left(g_{t-1}-g_{t-2}\right)\right]^{2}$.

${ }^{6}$ Bernanke and Blinder (1992) for United States, Aleem (2010) for India.
} 
Figure 3: Overnight interbank rate and the monetary policy stance

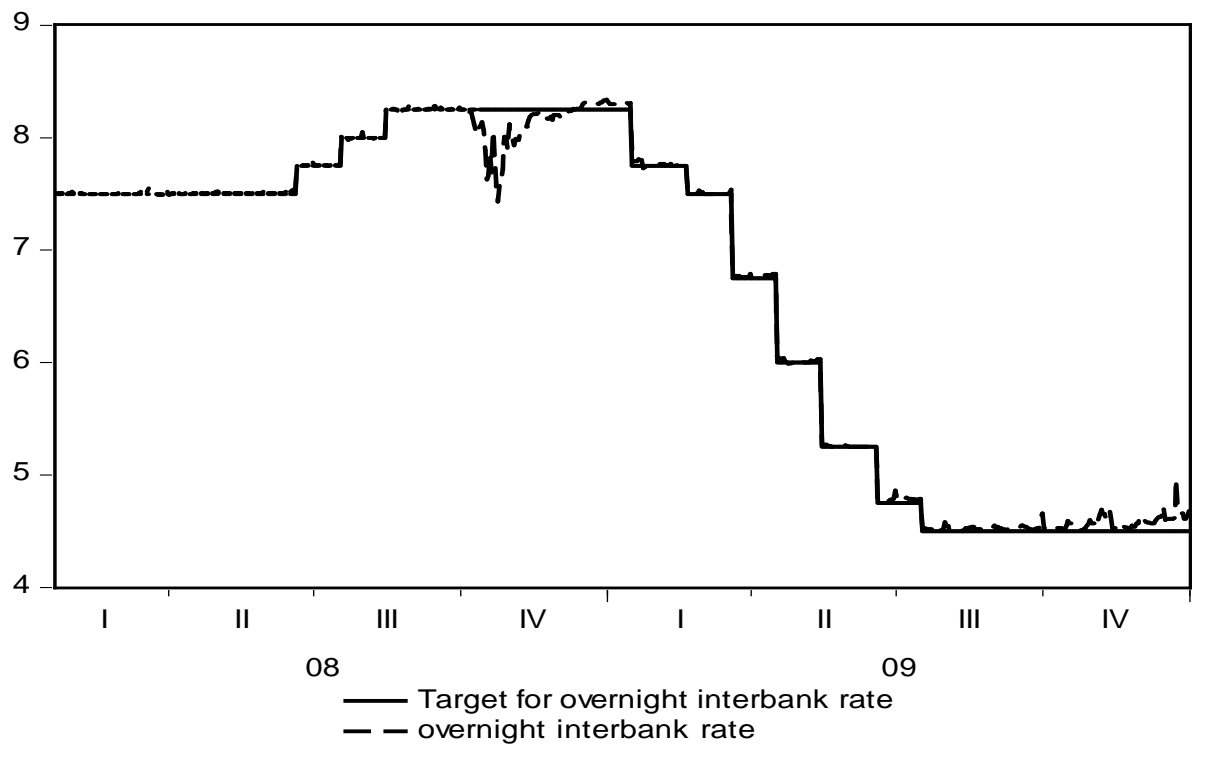

Source: Bank of Mexico

Figure 3 shows the overnight interbank rate and the target for overnight interbank rate. The overnight interbank rate follows the target rate. Hence, we use the overnight interbank rate as an indicator of monetary policy stance.

Before testing for thresholds in the Vector Autoregression representation of the data ${ }^{7}$, we select the optimal lag order by estimating the linear VAR model. The optimal lag order is determined by using the Akaike Information Criterion (AIC) which is the most widely used information criterion in the empirical literature of model selection. The AIC selects 3 as the optimal lag for the TVAR model.

\footnotetext{
${ }^{7}$ Johansen cointegration test shows that the cointegrating matrix is a full rank matrix. Thus, variables are stationary, and a TVAR model is estimated to examine the exchange rate pass-through.
} 


\subsection{The nonlinearity test}

We run a nonlinearity test for a threshold VAR model against a linear VAR model by using the rate of inflation as threshold variable. The rate of inflation below the threshold level constitutes a low inflation regime, and above the threshold level it constitutes a high inflation regime. The threshold values are the turning points at which either a significant exchange rate pass-through takes the place of an insignificant exchange rate pass-through, or an insignificant exchange rate pass-through takes the place of a significant exchange rate pass-through. To test the null hypothesis of linearity ( $m=1$ regime) against the alternative of nonlinearity ( $m=2,3$ regimes), we use a multivariate extension of the linearity test by Hansen (1999), and Lo and Zivot (2001). The test makes use of the covariance matrix of each model (models 0 and 1), i.e., model 0 is the simple VAR model (under the null of linearity) and model 1 is the TVAR model with one and two regimes, respectively. The LR test statistic is written as follows:

$$
L R_{01}=T\left(\ln \left(\operatorname{det} \quad \hat{\Sigma}_{0}\right)-\ln \left(\operatorname{det}\left(\hat{\Sigma}_{1}\right)\right)\right.
$$

where $\hat{\Sigma}_{0}$ is the estimated covariance matrix of the model under the null hypothesis and $\hat{\Sigma}_{1}$ is the estimated covariance matrix under the alternative. The calculation of the $\mathrm{p}$-value is done by simulation. The bootstrap distribution is based on resampling the residuals from the null model, estimating the threshold and computing the test. For all computations we use 1000 bootstrap replications. 
Table 1: LR test results

\begin{tabular}{|c|c|}
\hline \multicolumn{2}{|c|}{ Panel A: LR test for linearity against 2 regimes } \\
\hline LR Statistic & 253.492 \\
\hline p-value & $0.000]$ \\
\hline Estimated threshold & 0.171 \\
\hline Panel B: LR test for linearity against 3 regimes \\
\hline LR Statistic & 405.706 \\
\hline p-value & $0.171 ; 0.789$ \\
\hline Estimated thresholds & 138.674 \\
\hline Panel C: LR test for 2 regimes against 3 regimes \\
\hline LR Statistic \\
\hline p-value \\
\hline Estimated Threshold
\end{tabular}

Results of the threshold test are reported in Table 1. Results are obtained by using the middle $70 \%$ of sorted observations, based on Hansen's (1996) result that the optimal trimming is $15 \%$.

Results in table 1 show that the simultaneous dynamics of the Mexican economy are well described by a 3-regime TVAR model ${ }^{8}$. Hence, we accept the 3-regime TVAR model. Of course all the previous analyses examine the exchange rate pass-through dynamics by looking at the coefficient of nominal effective exchange rate in the inflation equation in different regimes.

\footnotetext{
${ }^{8} \mathrm{p}$-values $=0$ in table 1 indicates the rejection of the null of linearity.
} 
Table 2: Estimation results of the TVAR model: $\gamma$-variable: $\pi$

\begin{tabular}{|c|c|c|c|}
\hline & $\begin{array}{l}\text { Re gime } 1: \pi(-1) \leq 0.171 \\
\text { Percentage of observations }=18.7 \%\end{array}$ & $\begin{array}{l}\text { Re gime } 2: 0.171<\pi(-1) \leq 0.789 \\
\text { Percentage of observations }=62.6 \%\end{array}$ & $\begin{array}{l}\text { Re gime } 3: \pi(-1)>0.789 \\
\text { Percentage of observations }=18.7 \%\end{array}$ \\
\hline \multirow[t]{2}{*}{ Constant } & 0.181 & 0.072 & 0.702 \\
\hline & $(0.1455)$ & $(0.072)$ & $(0.251)^{* *}$ \\
\hline \multirow[t]{2}{*}{ Output gap (-1) } & -0.033 & 0.023 & 0.008 \\
\hline & $(0.0289)$ & $(0.010)^{*}$ & $(0.027)$ \\
\hline \multirow[t]{2}{*}{$\pi(-1)$} & 0.133 & 0.725 & 0.277 \\
\hline & $(0.3800)$ & $(0.159) * * *$ & $(0.244)$ \\
\hline \multirow[t]{2}{*}{$\operatorname{NEER}(-1)$} & -0.005 & -0.014 & 0.001 \\
\hline & $(0.0120)$ & $(0.011)$ & $(0.004)$ \\
\hline \multirow[t]{2}{*}{$i(-1)$} & 0.051 & 0.008 & 0.010 \\
\hline & $(0.039)$ & $(0.017)$ & $(0.007)$ \\
\hline \multirow[t]{2}{*}{ Output gap (-2) } & -0.055 & 0.030 & -0.006 \\
\hline & $(0.033)$ & $(0.012)^{*}$ & $(0.028)$ \\
\hline \multirow[t]{2}{*}{$\pi(-2)$} & -0.3684 & -0.136 & -0.376 \\
\hline & $(0.222)$ & $(0.111)$ & $(0.239)$ \\
\hline \multirow[t]{2}{*}{$\operatorname{NEER(-2)}$} & 0.016 & -0.004 & -0.0003 \\
\hline & $(0.014)$ & $(0.011)$ & $(0.004)$ \\
\hline
\end{tabular}

Note: Values in the brackets are the standard errors. * represents the $1 \%$ level of significance, $* *$ represents $5 \%$ level of significance, $* * *$ represents $10 \%$ level of

significance 
Table 2: Estimation results of the TVAR model: $\gamma$-variable: $\pi$ (Continued)

\begin{tabular}{|c|c|c|c|}
\hline & $\begin{array}{l}\operatorname{Re} \text { gime } 1: \pi(-1) \leq 0.171 \\
\text { Percentage of observations }=18.7 \%\end{array}$ & $\begin{array}{l}\text { Re gime } 2: 0.171<\pi(-1) \leq 0.789 \\
\text { Percentage of observations }=62.6 \%\end{array}$ & $\begin{array}{l}\text { Re gime } 3: \pi(-1)>0.789 \\
\text { Percentage of observations }=18.7 \%\end{array}$ \\
\hline \multirow[t]{2}{*}{$i(-2)$} & -0.112 & 0.007 & -0.002 \\
\hline & $(0.070)$ & $(0.027)$ & $(0.010)$ \\
\hline \multirow[t]{2}{*}{ Output gap (-3) } & -0.003 & 0.012 & -0.029 \\
\hline & $(0.021)$ & $(0.011)$ & $(0.022)$ \\
\hline \multirow[t]{2}{*}{$\pi(-3)$} & 0.115 & 0.011 & -0.015 \\
\hline & $(0.191)$ & $(0.097)$ & $(0.202)$ \\
\hline \multirow[t]{2}{*}{$\operatorname{NEER(-3)}$} & -0.015 & 0.007 & -0.009 \\
\hline & $(0.020)$ & $(0.008)$ & $(0.004) *$ \\
\hline \multirow[t]{2}{*}{$i(-3)$} & 0.065 & -0.009 & 0.001 \\
\hline & $(0.064)$ & $(0.016)$ & $(0.007)$ \\
\hline$A I C$ & & 646.625 & \\
\hline$\overline{S I C}$ & & 1157.140 & \\
\hline$S S R$ & & 4040.170 & \\
\hline
\end{tabular}

Note: Values in the brackets are the standard errors. * represents the $1 \%$ level of significance, ** represents $5 \%$ level of significance, $* * *$ represents $10 \%$ level of significance 


\section{Empirical results}

Table 2 reports the results of the TVAR model with the rate of inflation $(\pi)$ as a threshold variable. Although the econometric tests select a three-regime VAR model, the exchange rate pass-through is negative and statistically significant only in the upper regime $(\pi>0.783)$ at the third lag. In the lower regime $(\pi \leq 0.167)$ and the middle regime $(0.167<\pi \leq 0.783)$, the exchange rate pass-through is statistically insignificant.

Figure 4 depicts the accumulated impulse responses of output gap, domestic prices and interest rate to a positive one unit exchange rate shock. In regimes 1 and 2 , a positive one unit exchange rate shock results in positive output gap. In regime 3, it is negative. However, the responses of output gap are not statistically significant in any regime.

In regime 1, a positive one unit exchange rate shock leads to a decrease in domestic prices. In regime 2, domestic prices increase after a positive one unit exchange rate shock. But the response of domestic prices is statistically insignificant in the two regimes. In regime 3, domestic prices decline after a positive one unit exchange rate shock. The response of domestic prices is statistically significant in the third regime.

The empirical estimates suggest that the exchange rate pass-through dynamics are rather described by two regimes i.e., a lower inflation regime with statistically insignificant and weak exchange rate pass-through and a higher inflation regime with statistically significant and strong exchange rate pass-through. In other words, a monthly rate of inflation of $0.79 \%$ acts as a threshold between two regimes. ${ }^{9}$ When the rate of inflation is above the threshold level, the exchange rate pass-through is significant, and when the rate of inflation is below the threshold level, the exchange rate pass-through is insignificant.

\footnotetext{
${ }^{9}$ A monthly rate of inflation of $0.79 \%$ equals an annual rate of inflation of $9.48 \%$
} 
Figure 4. Accumulated impulse responses of output gap, inflation and monetary policy to a positive one unit exchange rate shock

Regime 1
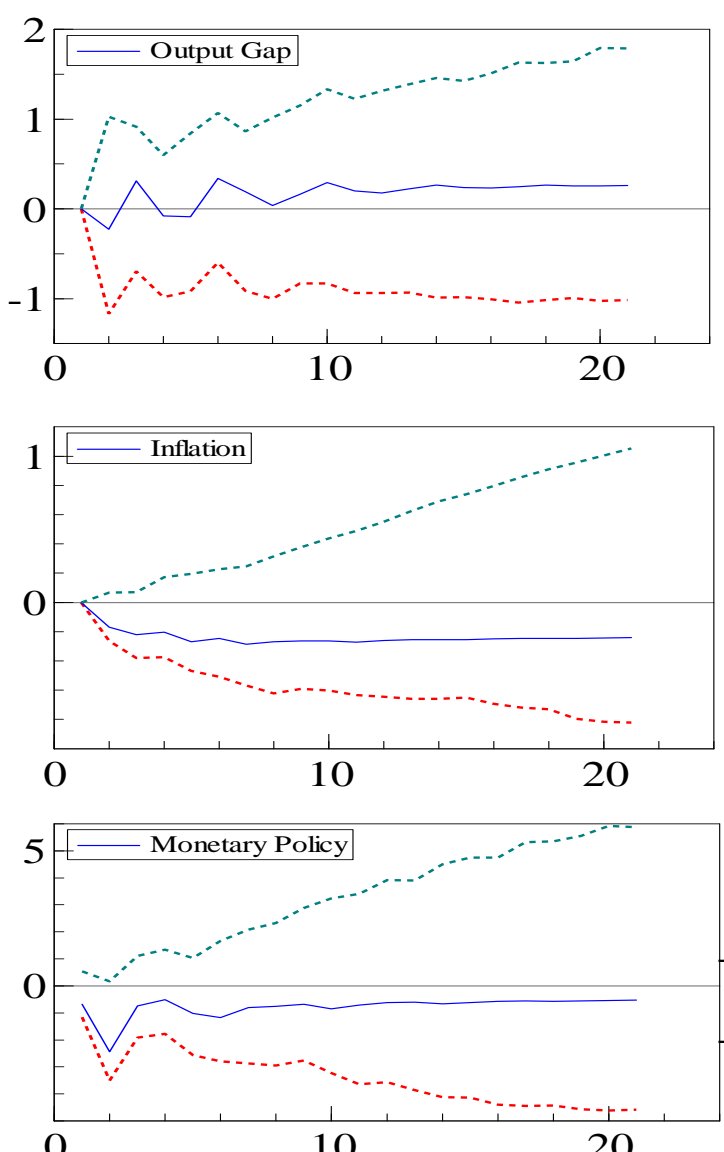

Regime 2
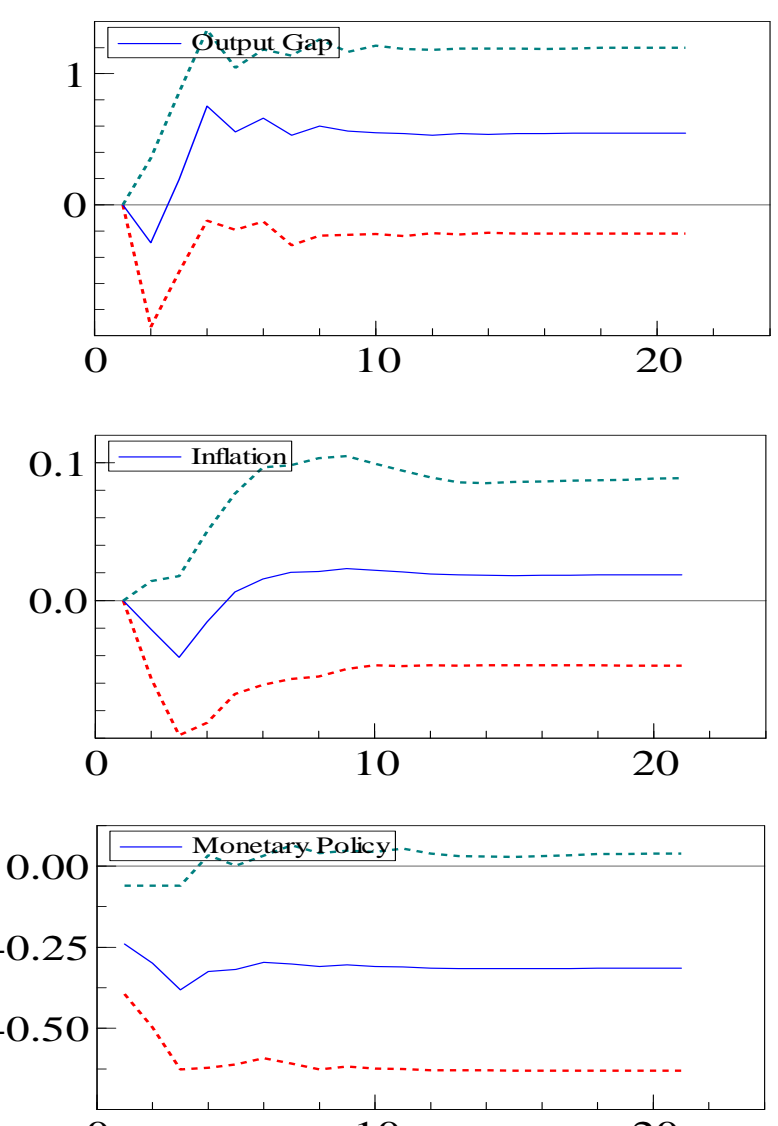

Regime 3
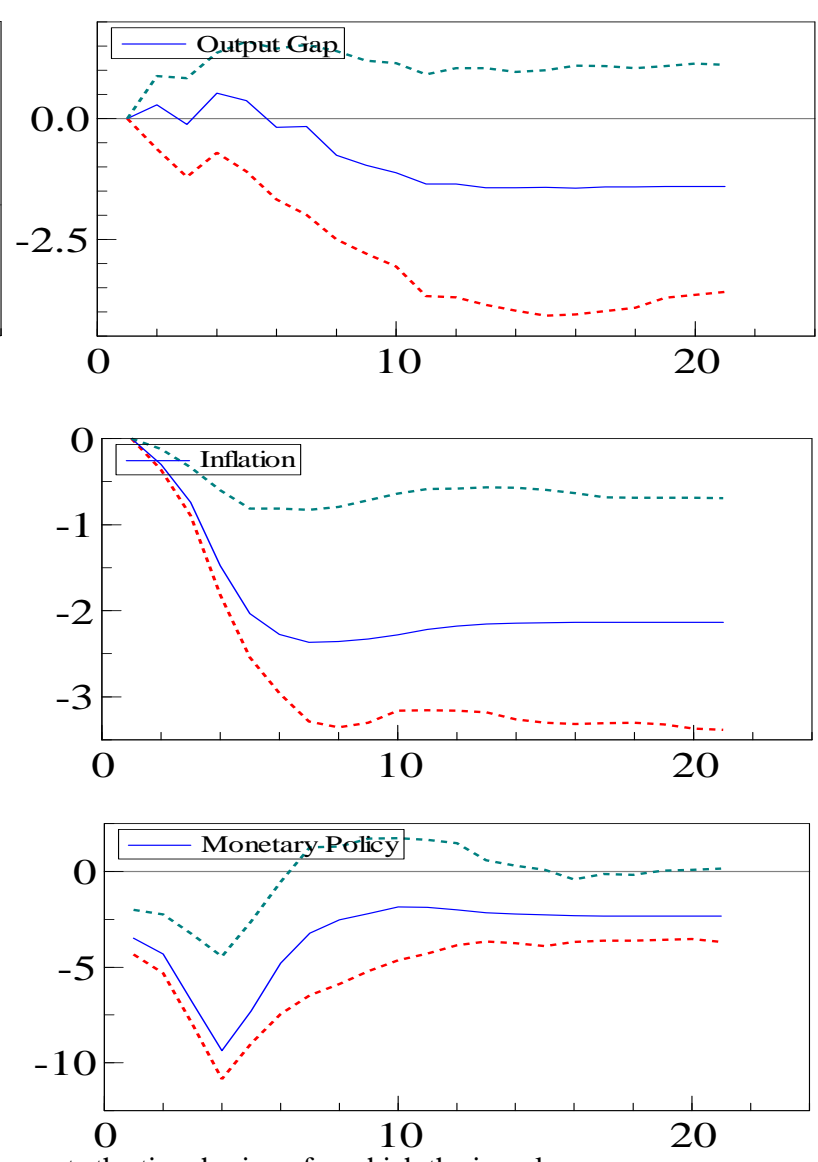

Note: Solid line indicates the impulse response function. Dashed lines are the $95 \%$ confidence intervals. Horizontal axis represents the time horizon for which the impulse response

is simulated and the vertical axis measures the magnitude of the response to a positive one unit NEER shock. 
Results of the TVAR model are consistent with the historical analysis of exchange rate depreciation and inflation in Mexico. Shaded areas in figure 2 show episodes of exchange rate depreciation in Mexico. The inflation responded strongly to first two episodes of exchange rate depreciation in high inflation regime, but it responded weakly to last two episodes of exchange rate depreciation in low inflation regime.

The central bank eases its monetary policy in response to a positive one unit exchange rate shock. The responses of monetary policy are statistically significant only in regimes 2 and 3 . A monthly rate of inflation of $0.17 \%$ acts as a threshold between two regimes. The response of monetary policy to an exchange rate shock is insignificant in the lower regime and significant in the middle and high regime, respectively.

\section{Conclusion}

The presence of menu costs and the adjustment of profit margins alters the reaction of economic agents to an exchange rate shock above and below a certain threshold level of the rate of inflation. We examine the exchange rate pass-through to domestic prices in Mexico by estimating a threshold vector autoregression (TVAR) model. The nonlinearity test for a TVAR model against a linear VAR model suggests the presence of three regimes with two threshold values of inflation. The threshold values of inflation are estimated endogenously. Based on the estimates of the TVAR model, we reduce three regimes with two threshold values of inflation to two regimes with one threshold value of inflation. The monthly rate of inflation of $0.79 \%$ acts as a threshold level between two regimes. We find that domestic prices in Mexico react strongly to a positive one unit exchange rate shock only above the threshold level of the rate of inflation. 
This empirical analysis provides important implications for policy makers and financial analysts. First, the Central Bank of Mexico should keep the inflation below 9.48\% to insulate domestic prices from exchange rate shocks. Second, the expected inflation is an important determinant of investment in securities markets. Inflation regimes in the TVAR model serve as leading indicator of exchange rate pass-through to domestic prices. As long as the annual rate of inflation is less than $9.48 \%$, the response of inflation to exchange rate shocks will be statistically insignificant. So, the expected inflation will not change significantly, ceteris paribus. 


\section{Acknowledgements}

Earlier version of this paper was presented in the ACEA conference at the University of Prince Edward Island, Canada, on October 15, 2011, and doctoral workshop of CEPN at the University of Paris XIII, on April $11^{\text {th }}, 2008$. We are grateful to the participants of the ACEA conference for their constructive comments.

\section{Appendix. Data sources}

Data on the Consumer Price Index (CPI) and the industrial production index are taken from the International Financial Statistics, International Monetary Fund. The data on the nominal effective exchange rate (NEER) are taken from the Bank for International Settlements (BIS). Data on overnight money market rate are taken from datasteam. 


\section{References}

Al-Abri, A.S., Goodwin, B.K., 2009. Re-examining the exchange rate pass-through into import prices using non-linear estimation techniques: Threshold cointegration. International review of economics and finance. 18, 142-161.

Aleem, A., 2010. Transmission mechanism of monetary policy in India. Journal of Asian Economics. 21, 186-197.

Alvarez, F., Neumeyer, A., Gonzalez-Rozada, M., Beraja, M., 2011. From hyperinflation to stable prices: Argentina's evidence on menu cost models. International economics workshop, October 17, 2011, Weatherhead Center for international affairs, Harvard University.

Baqueiro, A., Diaz de Leon, A., Torres, A., 2003. Fear of floating or fear of inflation? The role of the exchange rate pass-through. BIS papers No. 19. Monetary and Economic Department, Bank for International Settlements.

Bernanke, B., Blinder, A., 1992. The Federal funds rate and the channels of monetary transmission. American Economic Review. 82, 901-921.

Bhundia, A., 2002. An empirical investigation of exchange rate pass-through in South Africa. IMF Working paper No. 02/165. International Monetary Fund.

Billmeier, A., Bonato, L., 2004. Exchange rate pass-through and monetary policy in Croatia. Journal of Comparative Economics. 32, 426-444.

Brière, M., Signori, O., 2012. Hedging inflation risk in a developing economy: The case of Brazil. Research in international business and finance (2012), http://dx.doi.org/10.1016/j.ribaf.2012.04.003.

Choudhri, E., Faruqee, H., Hakura, D., 2005. Explaining the exchange rate pass-through in different prices. Journal of international economics. 65, 349-374. 
Goldfajn, I., Werlang, S., 2000. The pass-through from depreciation to inflation: A panel study. Discussion papers No. 423. Department of Economics, PUC-RIO.

Granville, B., Mallick, S., 2006. Does inflation or currency depreciation drive monetary policy in Russia? Research in international business and finance. 20, 163-179.

Hansen, B., 1996. Inference when a nuisance parameter is not identified under the null hypothesis. Econometrica. 64, 413-430.

Hansen, B., 1999. Testing for Linearity. Journal of Economic Surveys. 13, 551-576.

Josip, T., Petra, P., 2009. Threshold Autoregressive model of exchange rate pass-through effect: The case of Croatia. Eastern European Economics. 47, 43-59.

Korhonen, L., Wachtel, P., 2006. A note on exchange rate pass-through in CIS countries. Research in International Business and Finance. 20, 215-226.

Leigh, D., Rossi, M., 2002. Exchange rate pass-through in Turkey. IMF Working paper No. 02/204. International Monetary Fund.

Levin, A., Natalucci, F., Piger, J., 2004. The macroeconomic effects of inflation targeting. Federal Reserve Bank of St. Louis Review, July/August 2004, 86(4), pp. 51-80.

Lo, M., Zivot, E., 2001. Threshold cointegration and nonlinear adjustment to the law of one price. Macroeconomic Dynamics. 5, 533-576.

McCarthy, J., 1999. Pass-through of exchange rates and import prices to domestic inflation in some industrialised economies. BIS working papers, No. 79. Monetary and Economic department, Bank for International Settlements.

Nogueira, R.P.Jr., 2006. Inflation targeting and the role of exchange rate pass-through. Studies in economics, No. 0602, June 2006, Department of Economics, University of Kent. 
Nogueira, R.P.Jr., Leon-Ledesma, M., 2010. Does exchange rate pass-through respond to measures of macroeconomic instability? Journal of Applied Economics. 14, 167-180.

Pollard, P., Coughlin, C., 2004. Size matters: asymmetric exchange rate pass-through at the industry level. Working paper 2003-029C. Federal Reserve Bank of Saint Louis.

Schemidt-Hebbel, K., Werner, A., 2002. Inflation targeting in Brazil, Chile, and Mexico: Performance, credibility, and the exchange rate. Economía. 2, 31-89.

Sek, S.K., Kapsalyamova, Z., 2008. Pass-through of exchange rate into domestic prices: The case of four Asian countries. The International Journal of Economic Policy Studies. 3, 45-72.

Takatoshi, I., Kiyotaka, S., 2007. Exchange rate pass-through and domestic inflation: A comparison between East Asian and Latin American countries. REITI discussion papers series, 07-E-040.

Taylor, J., 2000. Low inflation, pass-through and the pricing power of firms. European Economic Review. 44, 1389-1408.

Zorzi, M., Hahn, E., Sanchez, M., 2007. Exchange rate pass-through in emerging markets. ECB working papers series, No. 739. European Central Bank 